\title{
Distribution of Phosphorus and Its Effects on Precipitation Behaviors and Tensile Properties of IN718C Cast Superalloy
}

\author{
An-Wen Zhang ${ }^{1,2} \cdot$ Yan Yang $^{3} \cdot$ Sha Zhang ${ }^{1} \cdot$ Dong Zhang ${ }^{3} \cdot$ Wei-Hong Zhang ${ }^{1} \cdot$ Da-Wei Han ${ }^{1} \cdot$ \\ Feng $\mathrm{Qi}^{1} \cdot$ Yuan-Guo $\operatorname{Tan}^{1,2} \cdot \mathrm{Xin} \mathrm{Xin}^{1} \cdot$ Wen-Ru Sun ${ }^{1}$
}

Received: 3 July 2018/Revised: 11 August 2018/Published online: 24 October 2018

(C) The Chinese Society for Metals and Springer-Verlag GmbH Germany, part of Springer Nature 2018

\begin{abstract}
The effect of phosphorus on the precipitations of $\gamma^{\prime \prime}, \gamma^{\prime}$ and $\delta$ phases and associated tensile properties in IN718C alloy are investigated in this study. It is revealed that $\mathrm{P}$ atoms are dissolved in the grain interior to a relatively high degree and hence influence the precipitation behaviors in the grain interior and improve the tensile strength of IN718C alloy. $\gamma^{\prime \prime}$ and $\gamma^{\prime}$ phases did not precipitate in the alloy without $\mathrm{P}$ addition during air cooling, while $\gamma^{\prime \prime}$ and $\gamma^{\prime}$ phases precipitated in the grain interior during air cooling in the alloys with P addition, and the amounts of $\gamma^{\prime \prime}$ and $\gamma^{\prime}$ phases increased with increasing P content. Therefore, the Vickers micro-hardness in the as-cast state increased gradually with increasing P content. In double-aging state, the sizes of $\gamma^{\prime \prime}$ and $\gamma^{\prime}$ phases in the alloys with $\mathrm{P}$ addition were larger than that in the alloy without $\mathrm{P}$ addition, while the sizes were invariable when the P content (wt\%) was higher than 0.015 . Therefore, the micro-hardness and tensile strength of IN718C alloy treated by double aging increased first and then kept invariable with increasing P content. The precipitations of $\delta$ phases both in the grain interior and on grain boundaries were inhibited by P markedly. The inhibitory effect of $\mathrm{P}$ on $\delta$ phase enhanced gradually with increasing content of $\mathrm{P}$, but the plasticity increased first and then decreased. What is more, the crack tended to propagate into the matrix around the particles (Laves phases and $\mathrm{NbC}$ carbides) in the alloys without $\mathrm{P}$ addition at the beginning of the tensile fracture, while it tended to propagate along the interfaces between the matrix and those particles in the alloys with $\mathrm{P}$ addition, which resulted from the synthetical effect of $\mathrm{P}$ on $\gamma^{\prime \prime}, \gamma^{\prime}$ and $\delta$ phases.
\end{abstract}

Keywords IN718C alloy $\cdot$ Phosphorus $\cdot \gamma^{\prime \prime}$ and $\gamma^{\prime}$ phases $\cdot \delta$ phase $\cdot$ Tensile properties

\section{Introduction}

Although phosphorus had been taken as a common impurity or a deleterious element in the superalloys and steels for a long time [1,2], it has been well documented recently that appropriate quantities of $\mathrm{P}$ could significantly prolong the creep and stress rupture lives of some superalloys

Available online at http://link.springer.com/journal/40195

Wen-Ru Sun

wrsun@imr.ac.cn

1 Institute of Metal Research, Chinese Academy of Sciences, Shenyang 110016, China

2 College of Material Science and Engineering, University of Science and Technology of China, Shenyang 110016, China

3 State Key Laboratory of Nickel and Cobalt Resources Comprehensive Utilization, Jinchang 737100, China including IN718 alloy [3, 4]. Some previous studies indicated that the creep and stress rupture lives of some superalloys increased first and then decreased rapidly with increasing content of P. For example, the optimal content of $\mathrm{P}$ is around 0.016 (wt\%) in GH761 alloy [3]; around 0.022 (wt\%) in IN718 alloy [5]; around 0.008 (wt\%) in IN706 alloy [6]; around 0.011 (wt\%) in GH4133 alloy [7]. Essentially, $\mathrm{P}$ is a trace element with strong segregation tendency and tends to be segregated at the defects such as the grain boundaries $[8,9]$. The previous study indicated that trace quantity of $\mathrm{P}$ had a variety of benefits, improving the grain-boundary cohesion $[10,11]$, enhancing the resistance to oxygen intrusion along the grain boundaries [12] and changing the grain-boundary precipitation $[11,12]$. It has been generally deemed that the beneficial effect of $\mathrm{P}$ on the superalloys was mainly attributed to the beneficial effect on grain boundaries [3, 12]. 
Some studies investigated the effects of $\mathrm{P}$ on the matrix strengthening and the tensile strength of wrought IN718 alloy. It has been revealed that $\mathrm{P}$ tended to be segregated at the grain boundaries, so it had almost no noticeable effect on the precipitations of $\gamma^{\prime \prime}$ and $\gamma^{\prime}$ phases in the grain interior of wrought IN718 alloy [10, 13]. Consequently, the tensile strength of the wrought IN718 alloy did not change obviously when the alloys were doped with various $\mathrm{P}$ contents [10].

As for $\mathrm{P}$ tends to be segregated at the grain boundaries $[8,9,14]$. The alloy with big grain size has limited $P$ atoms at grain boundaries, so the content of $\mathrm{P}$ in the grain interior can increase by decreasing the grain-boundary area. In the case, the effect of $\mathrm{P}$ on the grain interior may manifest apparently, and the most essential effect of $\mathrm{P}$ in superalloys may be revealed. Therefore, the roles of $\mathrm{P}$ in superalloys with big size grain should be investigated.

The IN718 alloy can be used as both the wrought superalloy and the cast superalloy, and it is named as IN718C when used as a cast superalloy. The beneficial effect of P in the wrought IN718 alloy has been widely investigated $[5,10]$, but few investigations have focused on the roles of $\mathrm{P}$ in the IN718C cast superalloy up to now. What is more, the IN718C cast superalloy is exactly that kind of alloy with the large grain size and limited $\mathrm{P}$ atoms at grain boundaries. Therefore, the IN718C cast superalloy was chosen in this study. The precipitation behaviors of the phases both in the grain interiors and on the grain boundaries with increasing content of $\mathrm{P}$ were investigated, and their synthetical effects on tensile properties of IN718C cast superalloy was also investigated in this study. The distribution of $\mathrm{P}$ and its effect on the grain boundaries and grain interiors in the superalloy were re-recognized.

\section{Materials and Experimental Procedures}

An IN718 master ingot was prepared via the vacuum induction melting (VIM). The analyzed composition (wt\%) of the master ingot was: $52.3 \mathrm{Ni}, 19.15 \mathrm{Cr}, 5.30 \mathrm{Nb}, 0.90$ $\mathrm{Ti}, 0.50 \mathrm{Al}, 3.08 \mathrm{Mo}, 0.005 \mathrm{~B}, 0.043 \mathrm{C}$ and balance Fe. Then, the master alloy was cut and remelted into five tensile specimen groups with a cylindrical dogbone geometry via VIM. The gauge diameter is $7.5 \mathrm{~mm}$, and the gauge length is $30 \mathrm{~mm}$. The alloys were doped with

Table 1 Analyzed contents (wt $\%$ ) of P in the alloys

\begin{tabular}{llllll}
\hline Alloy & 1 & 2 & 3 & 4 & 5 \\
\hline $\mathrm{P}$ & 0.001 & 0.015 & 0.022 & 0.025 & 0.035 \\
\hline
\end{tabular}

different contents of $\mathrm{P}$ during remelting. The analyzed $\mathrm{P}$ contents (wt\%) in the five alloys are shown in Table 1.

To study the effect of $\mathrm{P}$ on the precipitations of $\gamma^{\prime \prime}$ and $\gamma^{\prime}$ phases during double aging, the precipitations of $\gamma^{\prime \prime}$ and $\gamma^{\prime}$ phases during air cooling (AC) must be prevented. So water quenching (WQ) was performed during the standard heat treatment of IN718C, which was regime A in Table 2. After heat treated by regime $\mathrm{A}$, the microstructure was observed, and the Vickers hardness (HV) and tensile properties were tested at room temperature.

The microstructures of the alloys treated by regime A are not homogeneous because of the severe solidification segregation. The element segregation can lead to nonuniform precipitations of $\gamma^{\prime \prime}, \gamma^{\prime}$ and $\delta$ phases, which can cause inaccuracy when evaluating the effect of $\mathrm{P}$ on these phases. It is necessary to eliminate the element segregation. So a homogenizing heat treatment was performed, as shown in regime $\mathrm{B}$ in Table 2 . Then, the alloys were treated at the precipitation temperatures of $\gamma^{\prime \prime}, \gamma^{\prime}$ and $\delta$ phases for various times, respectively. The microstructure was observed subsequently, and the HV micro-hardness was measured at room temperature.

The standard tensile specimens were machined and tested at room temperature. The gage diameter is $5 \mathrm{~mm}$, and the gage length is $25 \mathrm{~mm}$. The fracture surfaces of the tensile specimens were examined using the scanning electron microscopy (SEM). The micro-hardness of the samples treated by homogenizing treatment was tested under a loading condition of $200 \mathrm{~g}$ for $15 \mathrm{~s}$. The microhardness of the samples treated by regime A was tested under a loading condition of $50 \mathrm{~g}$ for $15 \mathrm{~s}$. The microhardness values were an average of at least five measurements per sample, and all the micro-hardness values were measured in different grains. The microstructural observation was conducted on the optical microscope (OM), SEM and transmission electron microscopy (TEM). The compositions of the phase were analyzed and measured by the SEM equipped with an X-ray energy-dispersive spectroscopy (EDS).

\section{Results}

\subsection{Effect of $P$ on the Microstructures}

The as-cast microstructure of IN718C cast superalloy shows the morphology of dendrite [15-17]. No obvious differences are observed among the as-cast dendrite structures of the alloys with various $\mathrm{P}$ contents. However, the as-cast microstructures of the alloys with various $\mathrm{P}$ contents observed under higher magnification are different (Fig. 1). Many needle-like $\delta$ phases distribute around the Laves phase in alloy 1 , but they are not observed in the 
Table 2 Heat treatment regimes

\begin{tabular}{ll}
\hline$A$ & $1095{ }^{\circ} \mathrm{C} / 1.5 \mathrm{~h} \mathrm{WQ}+955^{\circ} \mathrm{C} / 1 \mathrm{~h} \mathrm{WQ}+720{ }^{\circ} \mathrm{C} / 8 \mathrm{~h} \frac{107 \min }{620}{ }^{\circ} \mathrm{C} / 8 \mathrm{~h} \mathrm{WQ}$ \\
$B$ & $1120{ }^{\circ} \mathrm{C} / 10 \mathrm{~h} \frac{5 \min }{1160{ }^{\circ} \mathrm{C} / 1 \mathrm{~h} \frac{5 \min }{1} 190{ }^{\circ} \mathrm{C} / 65 \mathrm{~h}}$ \\
\hline
\end{tabular}
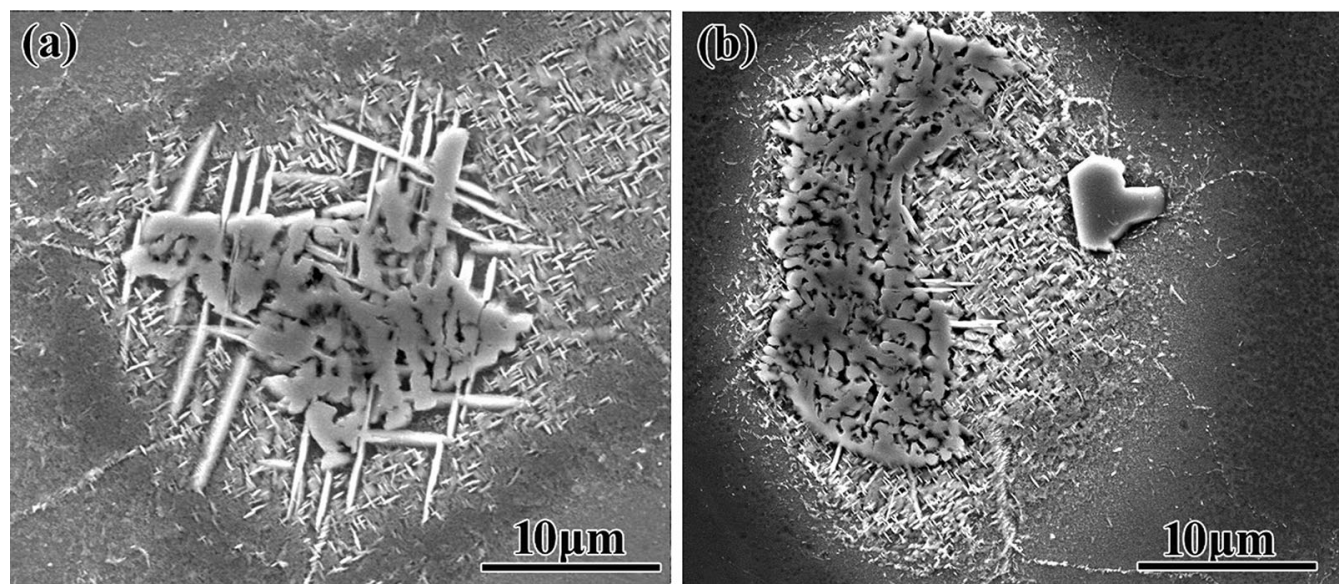

Fig. 1 Typical as-cast microstructures of IN718C alloys: a alloy 1; b alloy 5
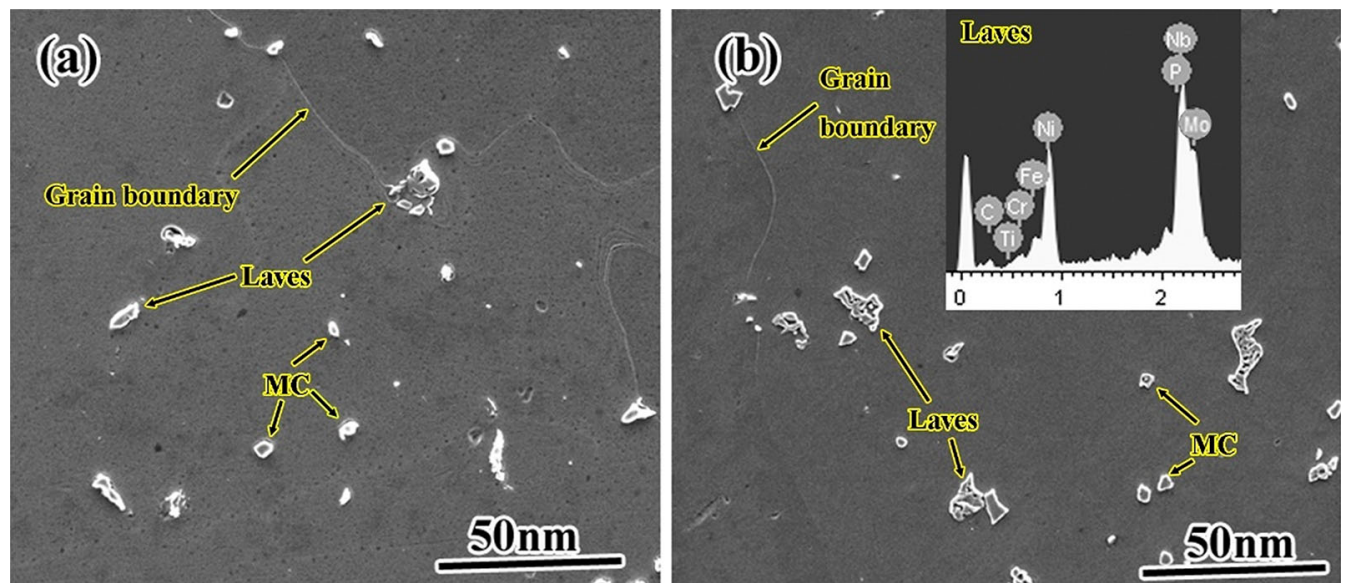

Fig. 2 Microstructures of the alloys heat treated by the first stage of regime A, $1095{ }^{\circ} \mathrm{C} / 1.5 \mathrm{~h}$ WQ: a alloy 1 ; b alloy 5

segregation region around the Laves phase in alloy 5. It indicates that the precipitation and growth of needle-like $\delta$ phase in the as-cast state of IN718C alloy are inhibited markedly by $\mathrm{P}$.

As shown in Fig. 2, when heat treated by the first stage of regime A, $1095{ }^{\circ} \mathrm{C} / 1.5 \mathrm{~h}$ WQ, the dendritic microstructures and needle-like $\delta$ phases disappear, and the grain boundaries of the alloys are exposed nakedly. In addition, the Laves phases are partly resolved, but the residual Laves phases in alloy 5 are much larger than those in alloy 1 . The Laves phases in the alloys with $\mathrm{P}$ addition are rich in $\mathrm{P}$, which consists with the previous study [18].

As shown in Fig. 3, when heat treated by the first two stages of regime A, $1095{ }^{\circ} \mathrm{C} / 1.5 \mathrm{~h} \mathrm{WQ}+955{ }^{\circ} \mathrm{C} / 1 \mathrm{~h} \mathrm{WQ}$, obvious differences are observed among the alloys with various $\mathrm{P}$ contents. The gain boundaries and interdendritic regions of alloys 1 and 2 are decorated with needle-like phases (Fig. 3a, b). However, some blocky particles are observed in the interdendritic regions of alloys 3 and 5 (Fig. 3c, d). The needle-like phases are $\delta$ phase, and the blocky particles are Laves phases and $\mathrm{NbC}$ (MC) carbides. It indicates that the precipitations of $\delta$ phases both on the grain boundary and in the grain interior are significantly inhibited by $\mathrm{P}$ addition, and the inhibitory effects are enhanced with increasing $\mathrm{P}$ content. What is more, there are more Laves phases in the matrix of alloy 5 (Fig. 3d), which consists with the results in Fig. 2b. The last stage of regime $\mathrm{A}$ is double aging, $720^{\circ} \mathrm{C} / 8 \mathrm{~h} \underline{107 \min } 620^{\circ} \mathrm{C} / 8 \mathrm{~h}$ WQ. Only $\gamma^{\prime \prime}$ and $\gamma^{\prime}$ phases precipitate in the matrix during double aging, so the microstructures of the alloys heat 

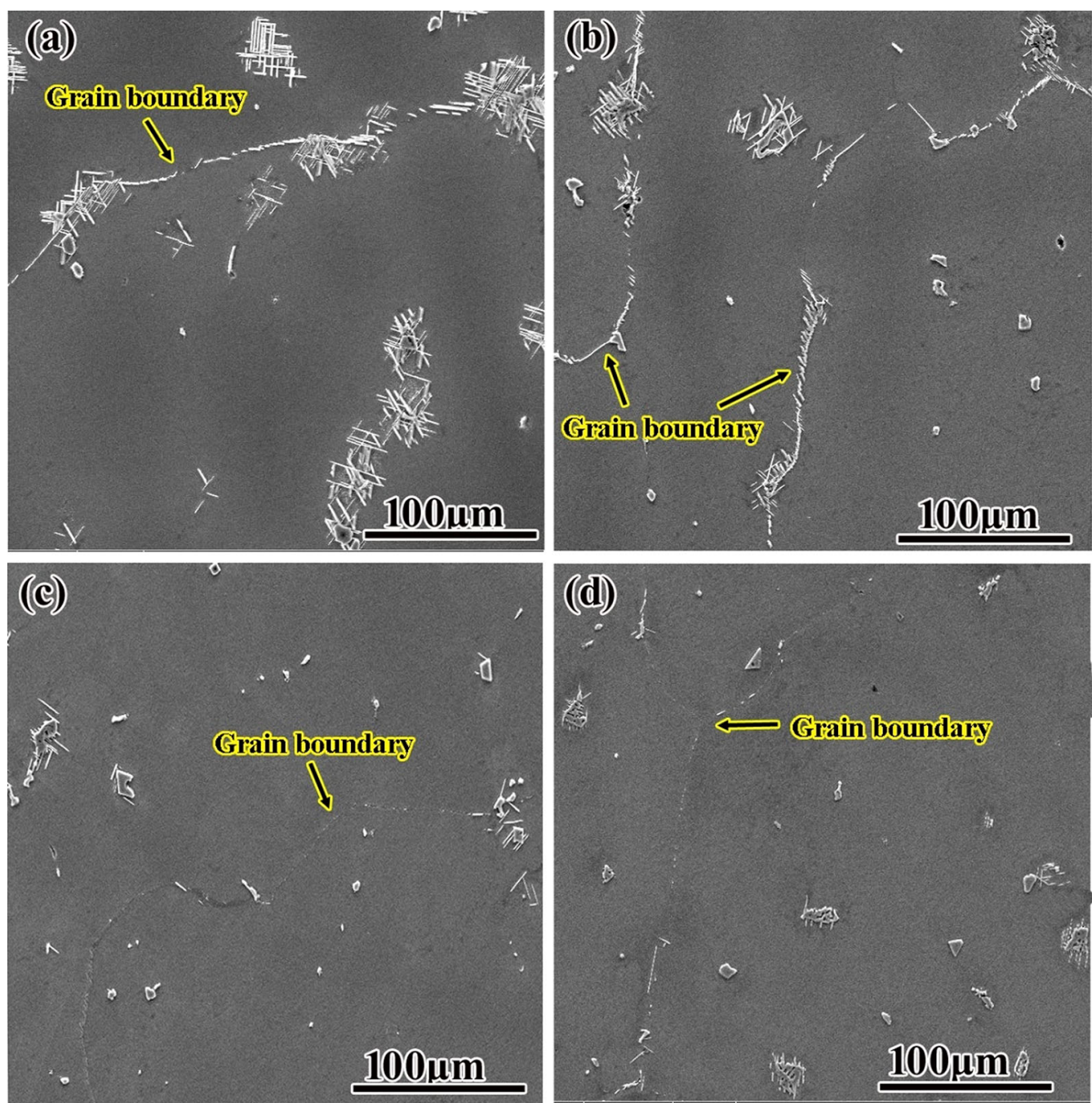

Fig. 3 Microstructures of the alloys with various $\mathrm{P}$ contents, heat treated by the first two stages of regime $\mathrm{A}, 1095{ }^{\circ} \mathrm{C} / 1.5 \mathrm{~h} \mathrm{WQ}+955{ }^{\circ} \mathrm{C} / 1 \mathrm{~h}$ WQ: a alloy $1 ; \mathbf{b}$ alloy $2 ; \mathbf{c}$ alloy $3 ; \mathbf{d}$ alloy 5

treated by regime A are exactly the same with those in Fig. 3.

$\mathrm{P}$ can influence the element segregation during casting $[16,17,19]$. To exclude the effect of the as-cast segregation on the precipitation of $\delta$ phase, the homogenizing heat treatment (regime B in Table 2) was performed to eliminate element segregation. The typical homogenizing microstructure is shown in Fig. 4a; only MC carbides and naked grain boundaries are observed. The homogenized samples are annealed at $955^{\circ} \mathrm{C}$ for $2 \mathrm{~h}$ followed by water quenching. As shown in Fig. 4, a great amount of barshaped $\delta$ phases precipitate on the grain boundary of alloy 1. However, the amount of $\delta$ phases on the grain boundary in alloy 5 is much less than that in alloy 1, which consists with the results in Fig. 3. So it is $\mathrm{P}$ atoms itself rather than the as-cast segregation to change the precipitation of $\delta$ phase.

\subsection{Effect of $P$ on the HV Micro-hardness of Matrix}

To investigate the effect of $\mathrm{P}$ on matrix strength, the HV micro-hardness changes of the alloys with various $P$ contents during heat treatment regime A were investigated. As shown in Fig. 5, the micro-hardness evolutions of the alloys with various $\mathrm{P}$ contents during the heat treatment regime $\mathrm{A}$ are different. In as-cast state, with increasing content of $\mathrm{P}$, the micro-hardnesses of both the dendrite arms and interdendritic regions increase gradually. It indicates that $\mathrm{P}$ can strengthen the matrix of IN718C alloy in as-cast state, and the strengthening effect of $\mathrm{P}$ is enhanced with increasing content of $\mathrm{P}$. What is more, the micro-hardness of the interdendritic region is markedly higher than that of the dendrite arm. In state I (the heat treated by the first stage of regime $\mathrm{A}$ ), the micro-hardnesses of the alloys with various $\mathrm{P}$ contents are the same. It indicates that $\mathrm{P}$ cannot influence the 

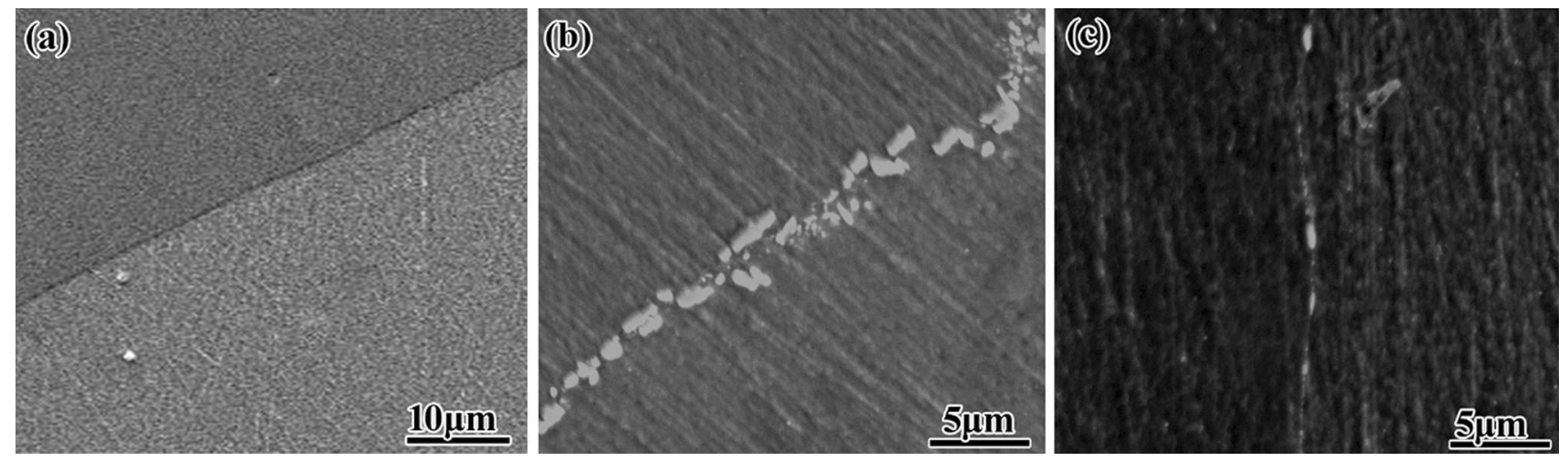

Fig. 4 Microstructures of the alloys with various $\mathrm{P}$ contents: a typical microstructure of the alloy heat treated by regime $\mathrm{B}+\mathrm{WQ}$; $\mathbf{b}$ alloy 1 , regime $\mathrm{B}+\mathrm{WQ}+955^{\circ} \mathrm{C} / 2 \mathrm{~h} \mathrm{WQ}$; c alloy 5 , regime $\mathrm{B}+\mathrm{WQ}+955^{\circ} \mathrm{C} / 2 \mathrm{~h} \mathrm{WQ}$

matrix strength of IN718C alloy soaked at high temperature followed by WQ. In addition, the micro-hardness of the interdendritic region is slightly higher than that of the dendrite arm. In state II (the heat treated by the first two stages of regime $\mathrm{A}$ ), the micro-hardnesses of the alloys with various $\mathrm{P}$ contents are the same with those in state I. In state III (the heat treated by the full regime A), the micro-hardnesses of the alloys are markedly higher than those in other states due to the precipitations of $\gamma^{\prime}$ and $\gamma^{\prime \prime}$ phases during double aging (the last stage of regime A). The dendrite arms and the interdendritic regions of the alloy 2 are significantly harder than those of alloy 1, respectively. However, the microhardnesses of alloys 3, 4 and 5 are the same as those of alloy 2. It indicates that $P$ can increase the micro-hardness of IN718C cast superalloy under treatment regime A, while the strengthening effect is invariable when the $\mathrm{P}$ content (wt\%) is higher than 0.015 . What is more, the micro-hardness of the interdendritic region is markedly higher than that of the dendrite arm. In summary, the matrix is markedly strengthened by $\mathrm{P}$ in the as-cast state and in double-aging state, but $\mathrm{P}$ cannot strengthen the matrix water quenched after annealing at high temperature.

\subsection{Effect of $\mathbf{P}$ on Tensile Properties at Room Temperature}

As shown in Fig. 6a, the yield strength of alloy 2 is higher than that of alloy 1 , but the yield strengths of alloys 3,4 and 5 are almost the same as that of alloy 2 . The ultimatestrength change is almost the same as the yield-strength change with increasing content of P. P can increase the tensile strength of IN718C alloy, but the strength is invariable when the $\mathrm{P}$ content (wt\%) is higher than 0.015 . Interestingly, the tensile-strength change in Fig. $6 \mathrm{a}$ is completely consistent with the micro-hardness change (state III in Fig. 5). As shown in Fig. 6b, the elongations of alloys 1,2 and 3 are almost the same, but the elongation decreases slightly when the $\mathrm{P}$ content (wt\%) is higher than
0.022. However, the reduction of area increases first and then decreases rapidly with increasing content of $\mathrm{P}$, and the alloy 3 has the highest reduction of area. The reduction of area of alloy 5 decreases to the same level of alloy 1 .

As shown in Fig. 7, no secondary cracks are observed on the fracture surfaces of alloys 1 and 2 (Fig. 7a, b). However, long secondary cracks are observed on the fracture surfaces of alloy 3 (Fig. 7c). Much more secondary cracks (indicated by arrows) are visible on the fracture surface of alloy 5 , and the size is very small (Fig. 7d). Therefore, $\mathrm{P}$ can promote the formation of secondary cracks during tensile fracture, and the secondary cracks can be formed obviously when the P content (wt\%) is higher than 0.022 .

At higher magnification, no secondary cracks are observed on the fracture surfaces of alloys 1 and 2 (Fig. 8a, b), while the intergranular cracks on the fracture surfaces of alloys 3 and 5 are observed (Fig. 8c, d). A large crack shows typical intergranular fracture feature on the fracture surface of alloy 5 (Fig. 8d). It indicates that the intergranular fracture is promoted when the $\mathrm{P}$ content (wt\%) is higher than 0.022 . Moreover, irregular dimples are observed on the fracture surface of alloy 1 (Fig. 8a), while some small holes were observed at the bottom of the dimples on the fracture surfaces of the alloys with $\mathrm{P}$ addition (Fig. 8b-d). It indicates that some phases in the alloys with $\mathrm{P}$ addition tend to be pulled out during tensile test.

To further investigate the fracture behavior of the alloys with various $P$ contents, longitudinal microstructures near the fractures were observed. As shown in Fig. 9a, many microcracks are observed in the matrix around the Laves phases and $\delta$ phases in alloy 1 , while cracks are observed at the Laves/matrix interfaces and MC/matrix interfaces in the alloys with $\mathrm{P}$ addition, and some Laves phases and MC carbides are broken up into small parts (Fig. 9b-d). So P addition can change the crack propagation path from the matrix around the particles (Laves phase, MC carbides and $\delta$ phase) to the interfaces of the matrix and the particles (Laves phases and MC carbides). 

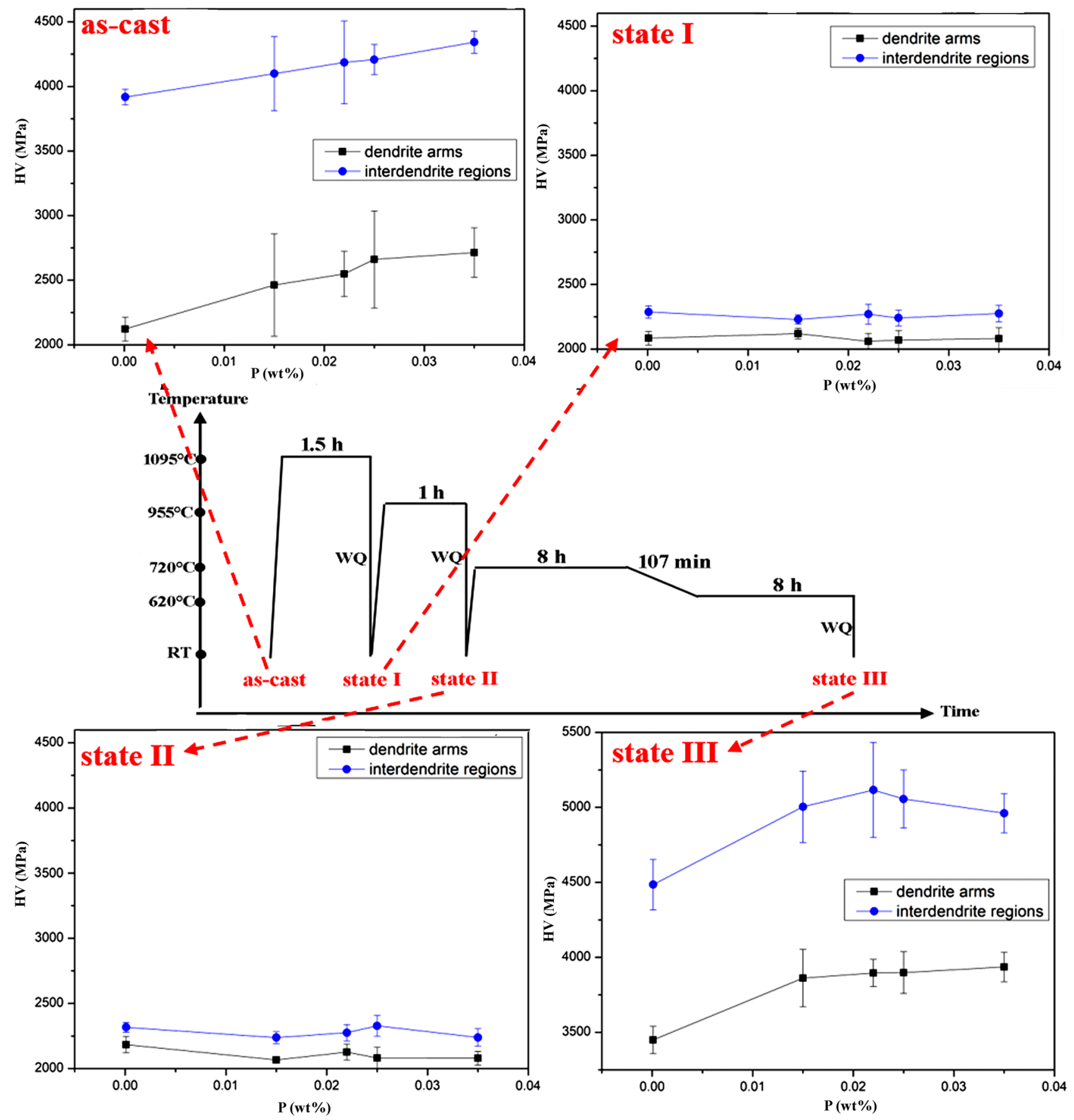

Fig. 5 Micro-hardness changes of the alloys with various $\mathrm{P}$ contents during treatment regime A

\section{Discussion}

\subsection{Effects of $P$ on $\delta$ Phases Both in the Grain Interior and on the Grain Boundary}

Although it has been generally deemed that $\mathrm{P}$ is surface active element with strong segregation tendency and tends to be segregated at the grain boundaries $[14,20,21]$, the $\delta$ phases both on the grain boundary and in the grain interior are inhibited by $\mathrm{P}$ in IN718C cast superalloy (Figs. 1, 3, 4). It indicates that $\mathrm{P}$ atoms are distributed both on the grain boundaries and in the grain interior of IN718C cast superalloy at the precipitation temperature of $\delta$ phase.

$\mathrm{Nb}$ is an important forming element for $\delta$ phase $\left(\mathrm{Ni}_{3} \mathrm{Nb}\right)$. The $\mathrm{Nb}$ atoms tend to be segregated to the interdendritic regions and Laves phases in IN718 alloy during solidification [22]. After the first stage of regime A, $1095{ }^{\circ} \mathrm{C} / 1.5 \mathrm{~h}$ 

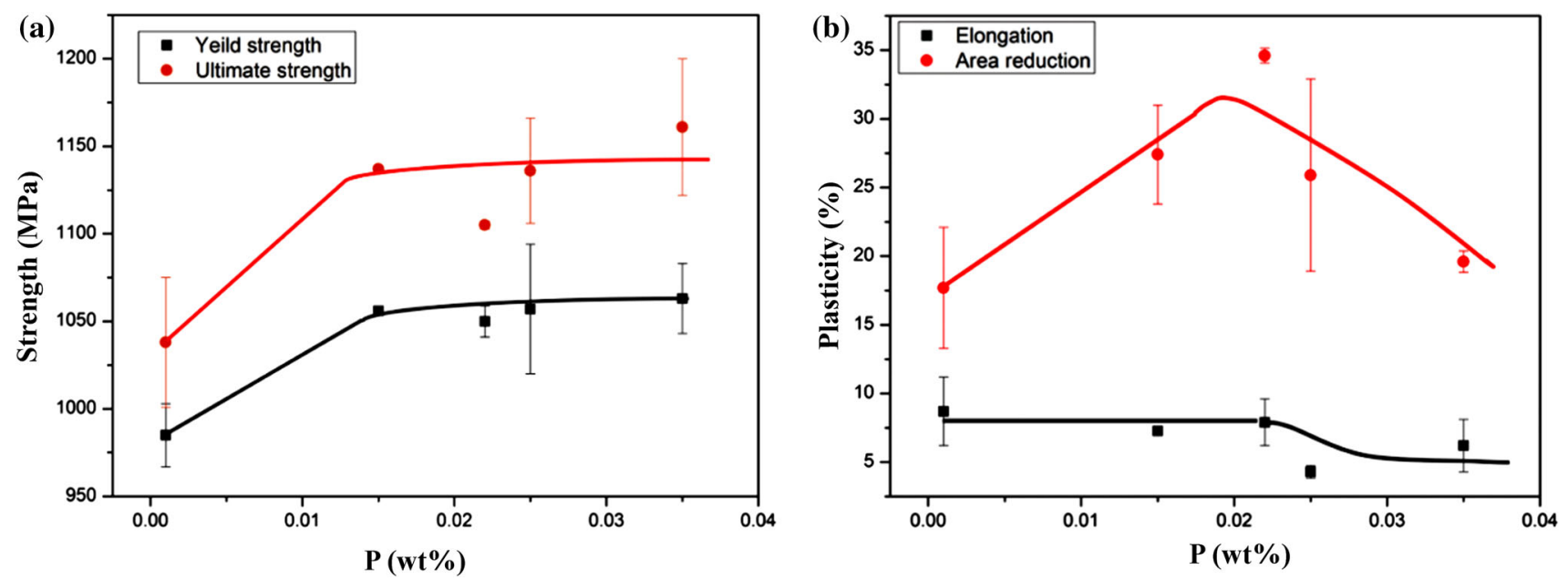

Fig. 6 Effect of $\mathrm{P}$ on tensile properties at room temperature of the alloys heat treated by regime A
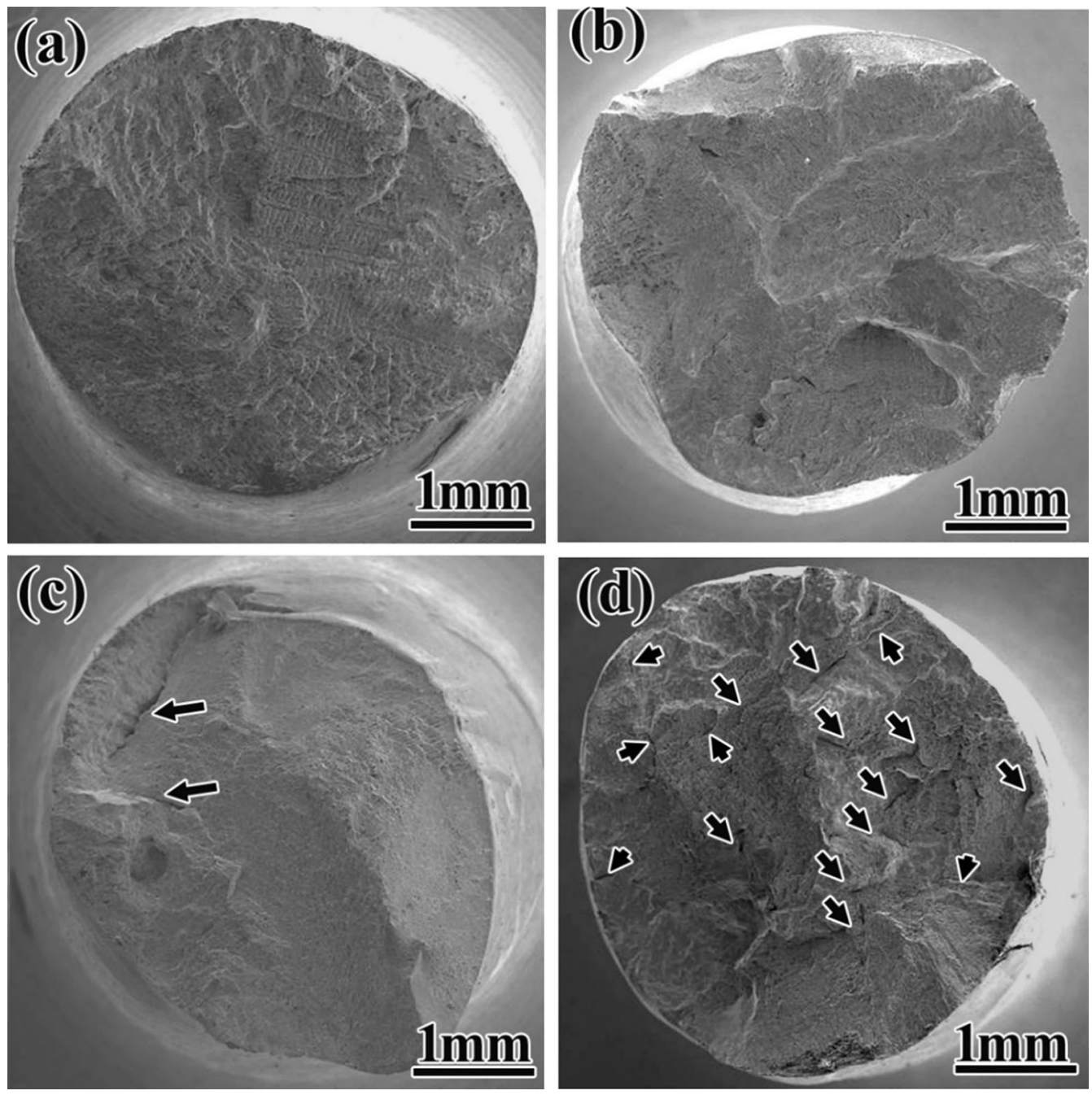

Fig. 7 Fractographs of the alloys with various P contents: a alloy 1; b alloy 2; c alloy 3; d alloy 5 

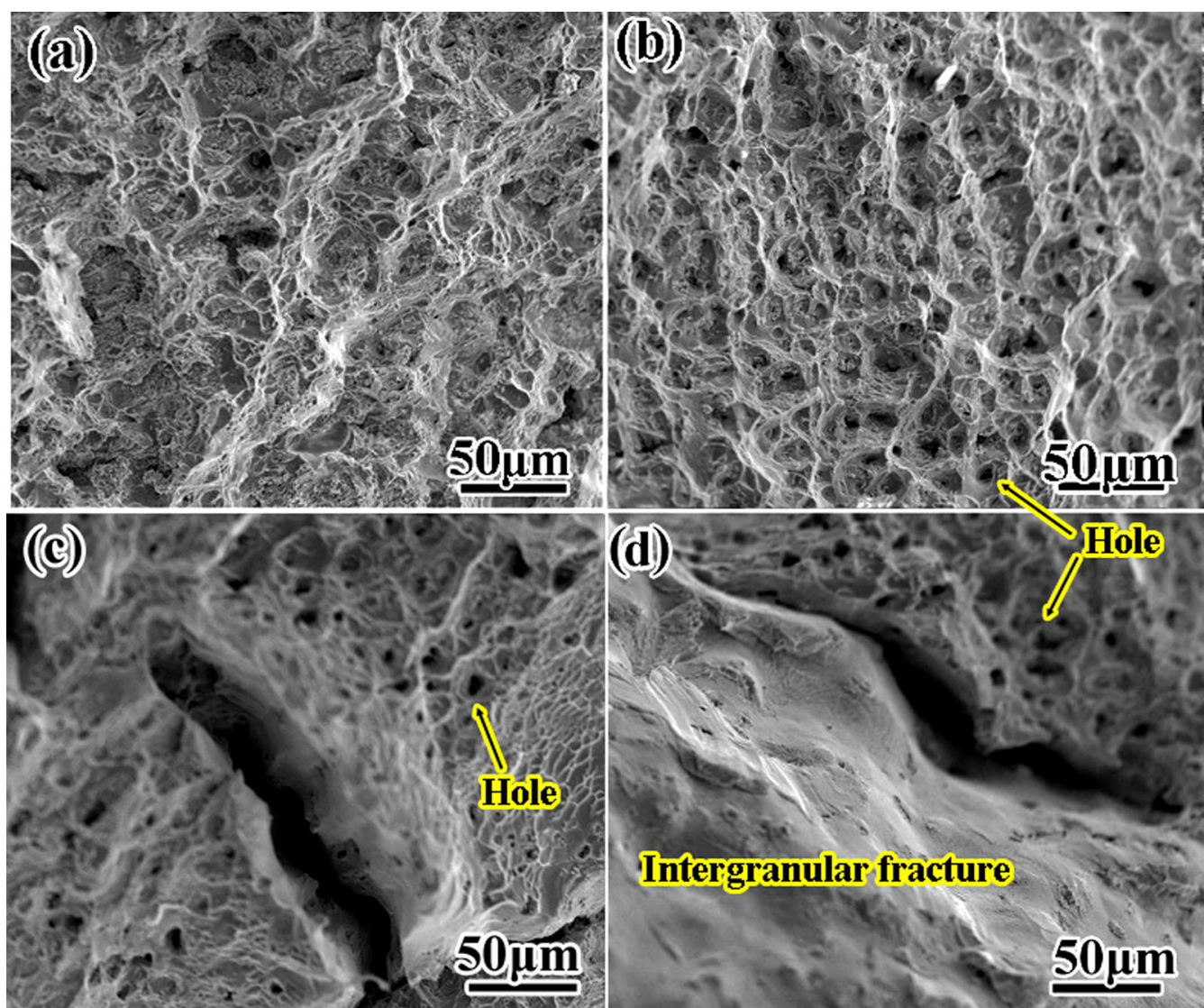

Fig. 8 Fractographs of the alloys with various $\mathrm{P}$ contents: a alloy 1 ; b alloy 2 ; $\mathbf{c}$ alloy 3 ; $\mathbf{d}$ alloy 5

WQ, some of the Laves phases and all the needle-like $\delta$ phases were dissolved (Fig. 2), and a great amount of $\mathrm{Nb}$ atoms were released into the surrounding matrix. Therefore, the interdendritic regions are rich in $\mathrm{Nb}$ after the first stage of regime A, which makes the needle-like $\delta$ phases subsequently precipitate in those regions during the second stage of regime A, $955{ }^{\circ} \mathrm{C} / 1 \mathrm{~h}$ WQ. Besides, the grain boundary is the position with high energy, which also facilitates the precipitation of $\delta$ phases [23]. As a result, $\delta$ phases are precipitated on the grain boundaries and in the interdendritic regions of alloy 1 under the first two stages of regime A (Fig. 3a). The previous studies showed that $\mathrm{P}$ atoms also tended to be segregated at Laves phases in superalloys during the solidification [17, 18], and $\mathrm{P}$ was a trace element and tended to be segregated to the grain boundaries [14, 20,21]. So the interdendritic regions and grain boundaries are rich in $\mathrm{P}$ when treated by the first stage of regime A, $1095{ }^{\circ} \mathrm{C} / 1.5 \mathrm{~h}$ WQ. Generally, P can decrease the Gibbs free energy of interfaces in alloys $[3,12]$. The change of Gibbs free energy for $\delta$ phase precipitation, $\Delta G$, can be illustrated as Eq. (1). $G^{\delta}$ denotes the free energy after the phase transformation; $G^{\text {interface }}$ denotes the interface's free energy before the phase transformation, which is bigger than $G^{\delta}$. The decrease in
$G^{\text {interface }}$ decreases the driving force of phase transformation. In the case, $\mathrm{P}$ atoms prevent the precipitation and growth of $\delta$ phases. The previous studies revealed that it was difficult for $\mathrm{P}$ to be dissolved in the $\delta$ phase $[11,12]$, which also results in the inhibition effect of $\mathrm{P}$ on $\delta$ phase.

$\Delta G=G^{\delta}-G^{\text {interface }}$

\subsection{Distribution of $\mathbf{P}$ in the Grain Interior and Its Effect on $\gamma^{\prime \prime}$ and $\gamma^{\prime}$ Phases}

The results in Fig. 5 indicate that $\mathrm{P}$ can increase the microhardness of the IN718C alloy in the as-cast state and double-aging state, but it has no influence on the matrix micro-hardness of the alloys annealed at high temperature and water quenching. As a precipitation strengthening alloy, the strength of IN718 alloy is mainly dominated by $\gamma^{\prime \prime}$ and $\gamma^{\prime}$ phases $[24,25]$. Therefore, the $\gamma^{\prime \prime}$ and $\gamma^{\prime}$ phases in the alloys with various $\mathrm{P}$ contents should be characterized.

To observe the $\gamma^{\prime \prime}$ and $\gamma^{\prime}$ phases in the alloys with various $\mathrm{P}$ contents, the homogenization treatment was performed. As shown in Fig. 10, when the regime B followed by $\mathrm{AC}$ is performed, the micro-hardness increases with increasing content of $\mathrm{P}$; when regime $\mathrm{B}$ followed by WQ is 


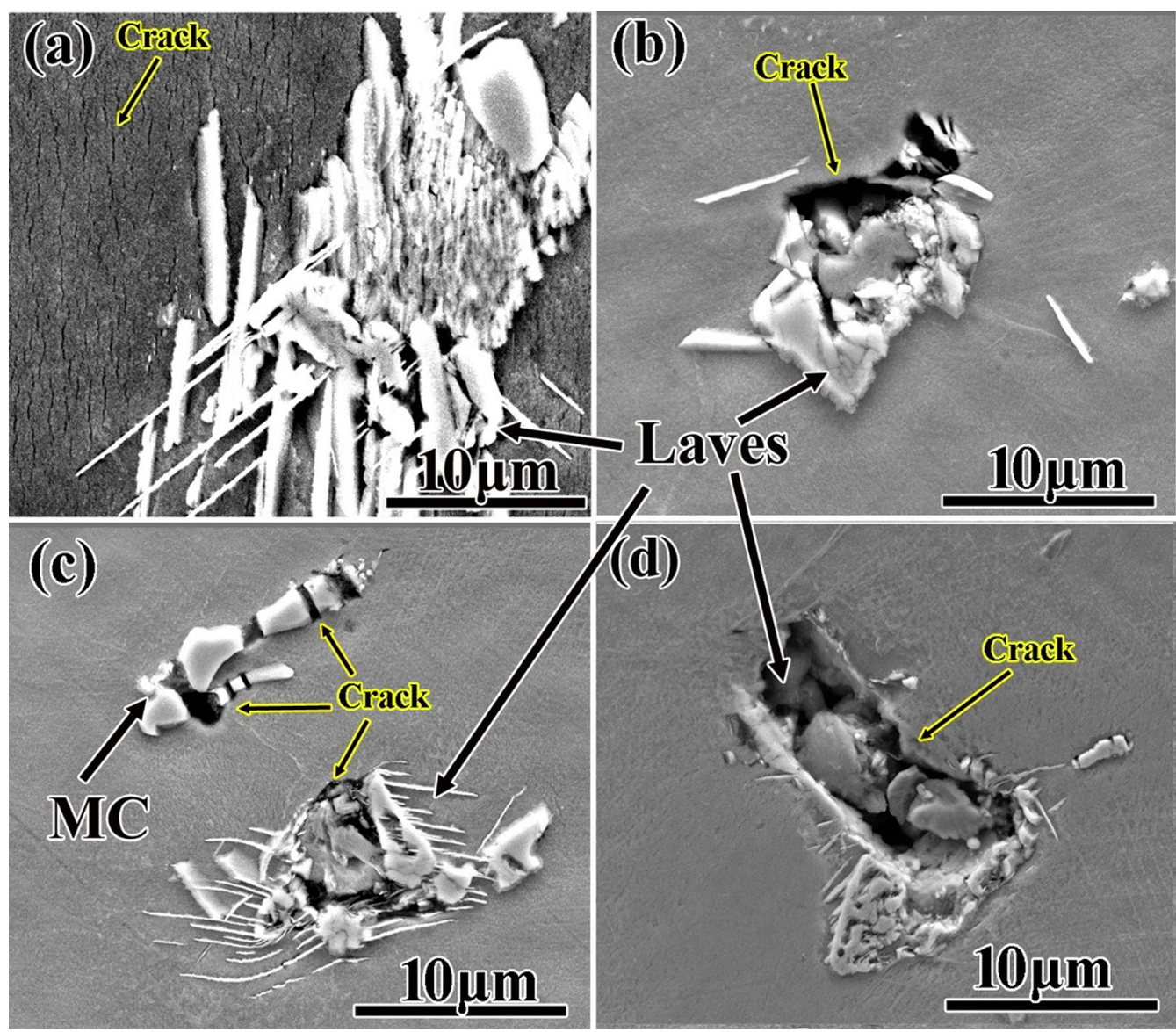

Fig. 9 Longitudinal microstructures near the fractures: a alloy 1 ; b alloy 2 ; $\mathbf{c}$ alloy 3 ; d alloy 5

performed, the micro-hardness does not change with increasing content of $\mathrm{P}$. The results in Fig. 10 consist with the results during the regime A treatment (as-cast, state I and state II in Fig. 5). As shown in Fig. 11, when regime B followed by WQ is performed, $\gamma^{\prime \prime}$ and $\gamma^{\prime}$ phases do not precipitate in the matrix of the alloys with various $\mathrm{P}$

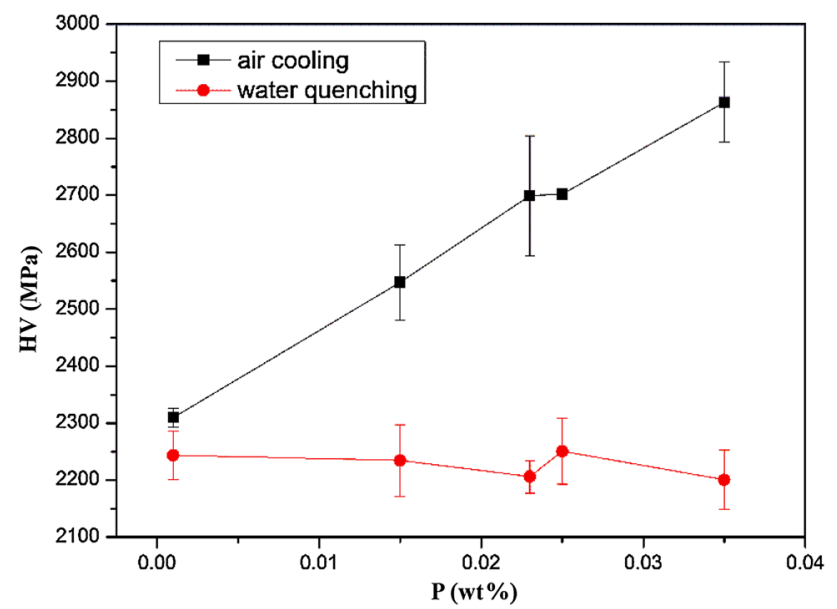

Fig. 10 Micro-hardnesses of the alloys with various $\mathrm{P}$ contents, heat treated by regime B followed by AC and WQ contents. When the regime B followed by AC is performed, $\gamma^{\prime \prime}$ and $\gamma^{\prime}$ phases do not precipitate in the matrix of alloy 1 , but both precipitate apparently in the matrix of the alloys with $\mathrm{P}$ addition. In addition, the amount of the two phases in the alloy 5 is much larger than that in alloy 2 . Therefore, $\mathrm{P}$ can accelerate the precipitations of $\gamma^{\prime \prime}$ and $\gamma^{\prime}$ phases during air cooling, and the amounts of $\gamma^{\prime \prime}$ and $\gamma^{\prime}$ phases increase with increasing content of $\mathrm{P}$. This indicates that more $\mathrm{P}$ atoms in the matrix proved more sites for nucleation during air cooling. As a consequence, $\mathrm{P}$ can increase the micro-hardness of the matrix in IN718C alloy (as-cast state in Figs. 5, 10), and the strengthening effect is enhanced with increasing content of P. In addition, $\mathrm{P}$ has no effect on the precipitations of $\gamma^{\prime \prime}$ and $\gamma^{\prime}$ phases during water quenching. It is because the high cooling rate (WQ) prevents the $\gamma^{\prime \prime}$ and $\gamma^{\prime}$ phases from precipitation (Fig. 11ac), which makes the effect of $\mathrm{P}$ on the precipitations of $\gamma^{\prime \prime}$ and $\gamma^{\prime}$ phases disappear.

In order to investigate the effect of $\mathrm{P}$ on the microhardness of the alloys under treatment regime $\mathrm{A}$, the double-aging treatment is performed after homogenization subsequently. As shown in Fig. 12, the micro-hardness of the alloy 2 is higher than that of alloy 1 , but the micro- 


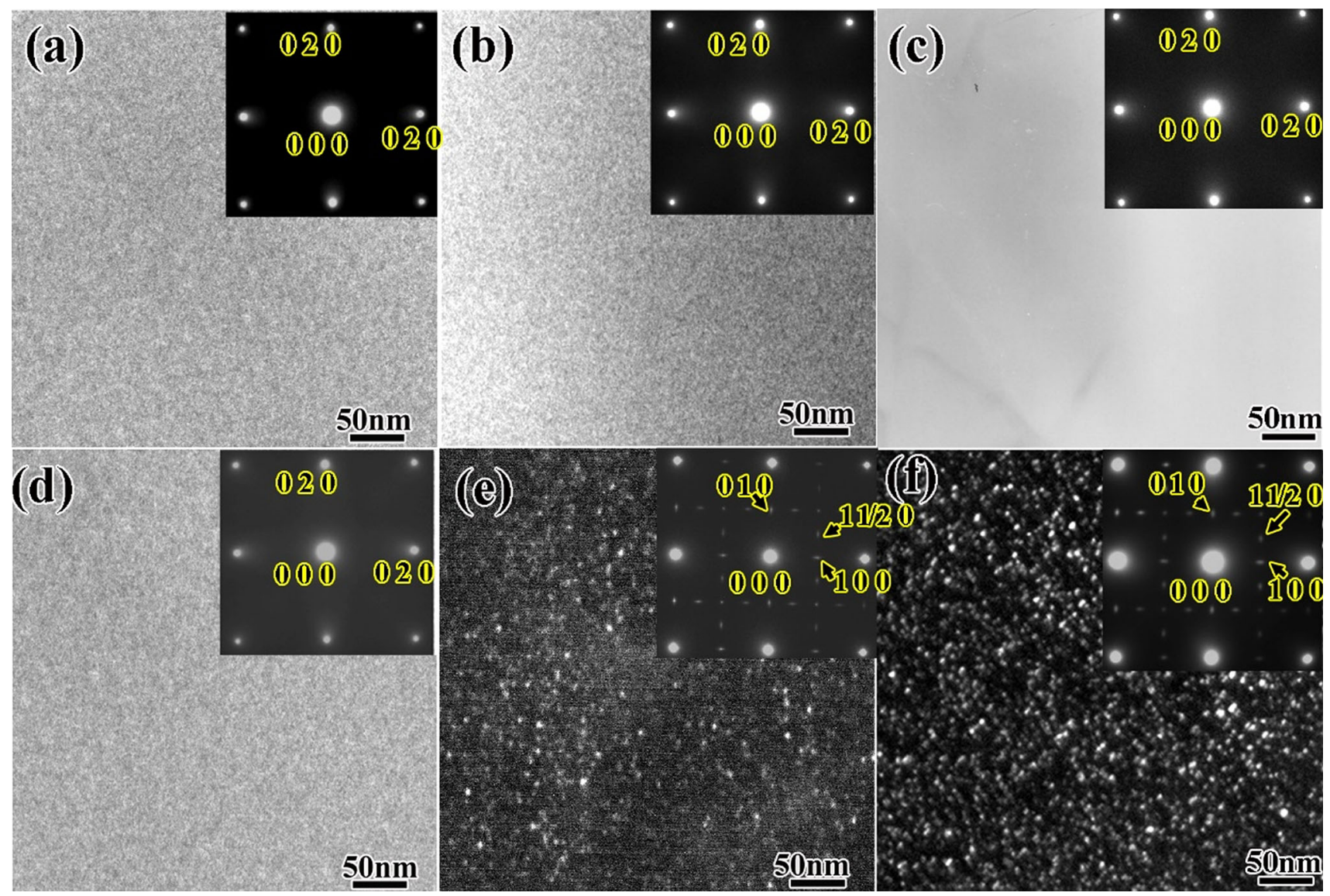

Fig. 11 TEM images and corresponding SAED patterns with [001] zone axis: a alloy 1, WQ, bright-field image; b alloy 2, WQ, bright-field image; $\mathbf{c}$ alloy 5, WQ, bright-field image; $\mathbf{d}$ alloy 1, AC, bright-field image; e alloy 2, AC, dark-field image of $\gamma^{\prime \prime}$ and $\gamma^{\prime}$ phases, (0 1 0) direction; f alloy 5, AC, dark-field image of $\gamma^{\prime \prime}$ and $\gamma^{\prime}$ phases, $\left(\begin{array}{lll}0 & 1 & 0\end{array}\right)$ direction

hardness does not increase sustainably with increasing $\mathrm{P}$ content, which consists with the micro-hardness change of the alloys under treatment regime A (state III, Fig. 5). The sizes of $\gamma^{\prime \prime}$ and $\gamma^{\prime}$ particles of the alloy 2 are bigger than those of alloy 1 , while the sizes of $\gamma^{\prime \prime}$ and $\gamma^{\prime}$ particles of the alloy 5 are almost the same as those of alloy 2 . In another word, $\mathrm{P}$ can increase the sizes of $\gamma^{\prime \prime}$ and $\gamma^{\prime}$ phases after double aging, but the sizes of $\gamma^{\prime \prime}$ and $\gamma^{\prime}$ phases do not increase sustainably when the $\mathrm{P}$ content (wt\%) is higher than 0.015. The $\gamma^{\prime \prime}$ phase is the main strengthening phase in IN718 alloy, and the tetragonal distortion associated with the $\gamma^{\prime \prime}$ particles has been found to increase with increasing of the precipitation size [26]. Therefore, the micro-hardness of alloys with $\mathrm{P}$ addition is higher than that of alloy 1 .

The coalescing occurs during the growth of the $\gamma^{\prime \prime}$ and $\gamma^{\prime}$ particle, so the quantities of the $\gamma^{\prime \prime}$ and $\gamma^{\prime}$ particles after double aging (Fig. 12) are smaller than those after air cooling (Fig. 11f). The previous study also revealed that the quantities of the $\gamma^{\prime \prime}$ and $\gamma^{\prime}$ particles decreased when the precipitates were fully grown [27], which consists with the results in this study. Therefore, when the time for precipitation is long, such as double aging, the quantities of $\gamma^{\prime \prime}$ and $\gamma^{\prime}$ particles are smaller in the alloys with $\mathrm{P}$ addition (Fig. 12), because $\mathrm{P}$ accelerates the precipitations of the two phases.

The forming element of $\gamma^{\prime \prime}-\mathrm{Ni}_{3} \mathrm{Nb}$ phase, $\mathrm{Nb}$, tends to be segregated in the interdendritic region in IN718 alloy $[17,28]$, so the volume fraction of $\gamma^{\prime \prime}$ phase in interdendritic region is naturally larger than that in the dendritic arm. In the case, the micro-hardness of interdendritic region is markedly higher than that of dendritic arm during regime A treatment (as-cast state and state III in Fig. 5). In addition, the solid-solution strengthening elements, $\mathrm{Nb}$ and Mo, tend to be segregated in the interdendritic regions in IN718 alloy during solidification [17, 28], which makes the micro-hardness of interdendritic regions slightly higher than that of dendritic arms when the precipitations of $\gamma^{\prime \prime}$ and $\gamma^{\prime}$ phases are prevented by WQ (states I and II in Fig. 5).

$\mathrm{P}$ atoms are frozen in the lattice of $\gamma$ matrix during water quenching, while the micro-hardnesses of the alloys with various $\mathrm{P}$ contents are almost equal (Figs. 5, 10). Therefore, the solution strengthening effect of $\mathrm{P}$ atoms on the matrix strength can be ignored even when the $\mathrm{P}$ content 


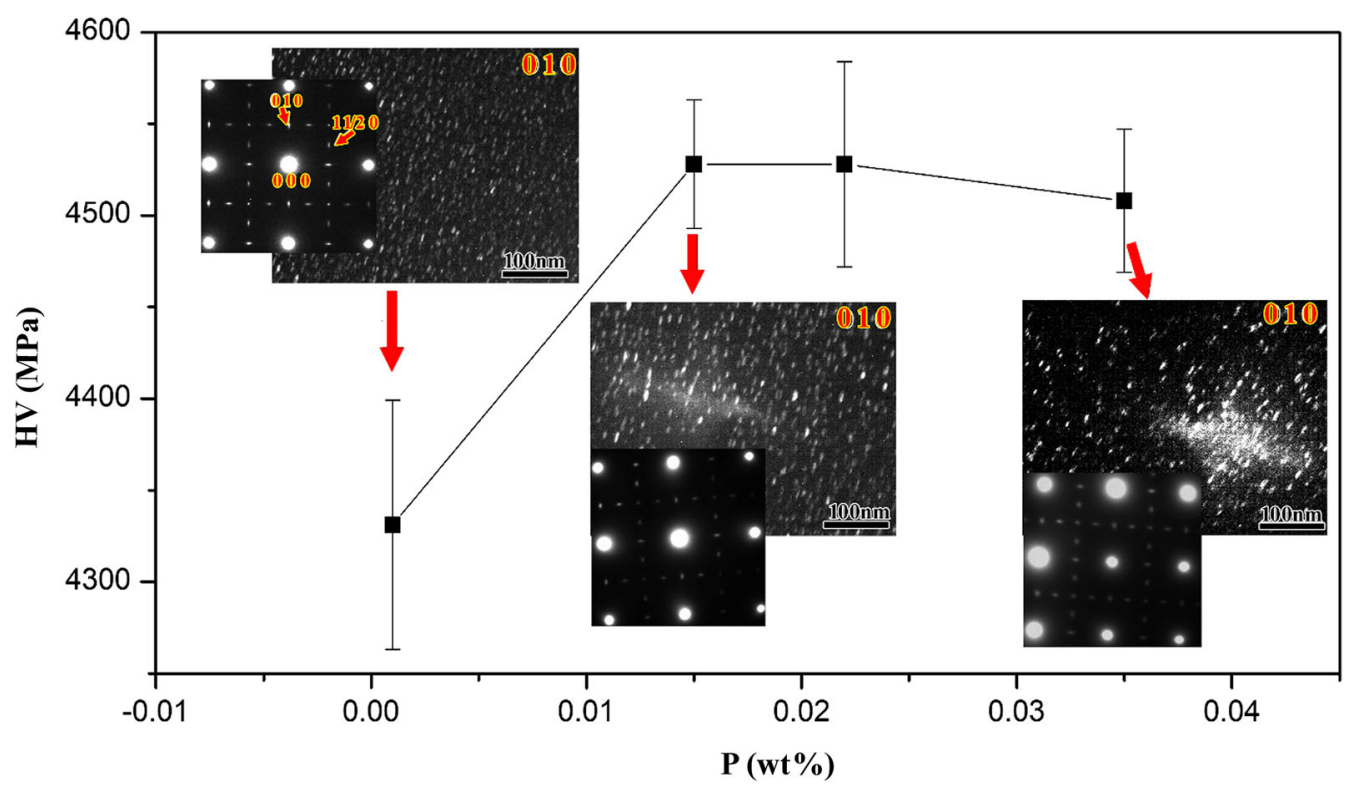

Fig. 12 Micro-hardnesses and corresponding TEM microstructures of the alloys with various P contents treated by the regime B followed by water quenching and double aging

(wt\%) in the alloy is as high as 0.035 , and the increase in micro-hardness of the alloys with $\mathrm{P}$ addition mainly results from the effect of P on $\gamma^{\prime \prime}$ and $\gamma^{\prime}$ phases in IN718C alloy.

\subsection{Effects of $P$ on the Fracture Behaviors and Tensile Properties}

The sizes of $\gamma^{\prime \prime}$ and $\gamma^{\prime}$ phases in alloy 2 are bigger than those in alloy 1 , which makes the matrix strength of alloy 2 higher than that of alloy 1 (state III in Fig. 5). So the tensile strength of alloy 2 is obviously higher than that of alloy 1 (Fig. 6a). However, when the P content (wt\%) is higher than 0.015 , the size of $\gamma^{\prime \prime}$ and $\gamma^{\prime}$ phases does not increase markedly with increasing content of P (Fig. 12), which makes the tensile strength invariable (Fig. 6a).

The previous study demonstrated that $\mathrm{P}$ tended to be segregated at the grain boundaries [14, 20, 21]. In the case, it had almost no noticeable effect on the precipitations of $\gamma^{\prime \prime}$ and $\gamma^{\prime}$ phases in wrought IN718 alloy, and the tensile properties of wrought IN718 alloy did not change obviously with the addition of $\mathrm{P}[10,13]$. However, this study reveals that $\mathrm{P}$ has obvious effects on the precipitations of $\gamma^{\prime}$ and $\gamma^{\prime \prime}$ phases and corresponding tensile strength in the IN718C cast alloy with bigger grain size. This indicates that the effects of $\mathrm{P}$ on the precipitations of $\gamma^{\prime}$ and $\gamma^{\prime \prime}$ phases and corresponding tensile strength are more noticeable when the grain size is big. The effect of $\mathrm{P}$ in wrought IN718 alloy and IN718C cast alloy is different because the IN718C cast alloy has much bigger grain size and smaller grain-boundary area. The IN718C alloy with small grain-boundary area has limited grain boundary to contain $\mathrm{P}$ atoms, which makes the contents of $\mathrm{P}$ in the grain interior relatively high. Therefore, the effects of $\mathrm{P}$ on the $\gamma^{\prime \prime}$ and $\gamma^{\prime}$ phases and tensile strength of IN718C cast alloy are more remarkable.

The interfaces of the matrix and phases (Lave, $\delta$ and MC) are stress concentration zones during deformation, and the cracks tend to be initiated at those places. With continuous increase of local stress, there are three paths for cracks to propagate subsequently: propagating along the interfaces of the matrix and phases (Lave, $\delta$ and MC), propagating into the surrounding matrix, propagating into the phases (Lave, $\delta$ and MC) and breaking those phases. The cracks certainly tend to propagate with the easiest path firstly. The results in Fig. 9 indicate that the cracks tend to propagate toward the matrix around the phases (Lave, $\delta$ and $\mathrm{MC}$ ) in alloy 1 , while the cracks tend to propagate along the interfaces of the matrix and phases (Lave, $\delta$ and $\mathrm{MC}$ ) or into the Laves and MC phases in the alloys with $\mathrm{P}$ addition. The different fracture behaviors in the alloys with various $\mathrm{P}$ contents are discussed as follows.

The $\delta$ phases in the interdendritic regions consume much $\mathrm{Nb}$ during precipitation, which decreases the concentration of $\mathrm{Nb}$ in the matrix around the $\delta$ phase. So the precipitation of $\gamma^{\prime \prime}$ around the $\delta$ phase is inhibited, and the matrix strength is relatively low. With continuous increase of local stress, cracks tend to propagate toward the matrix around the $\delta$ phases and Laves phases in alloy 1 (Fig. 9a). For the other four alloys, the addition of $\mathrm{P}$ can prevent the precipitation of $\delta$ phases from the interdendritic regions, which makes the concentration of $\mathrm{Nb}$ in the interdendritic regions higher than alloy 1 . What is more, $\mathrm{P}$ itself can 


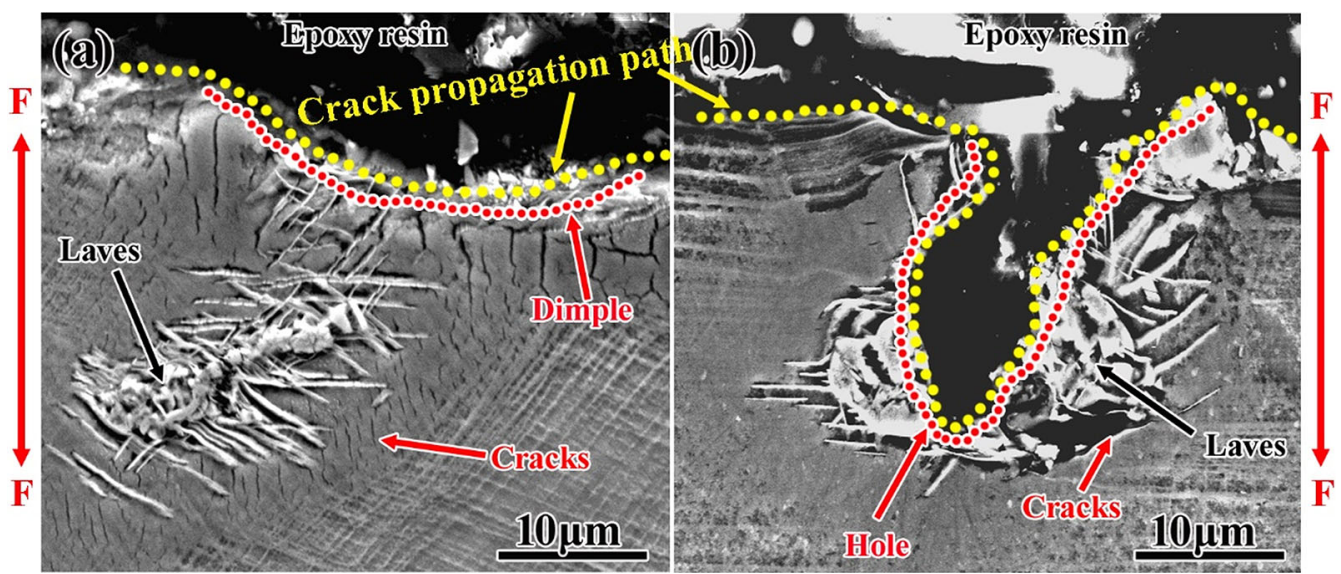

Fig. 13 Longitudinal microstructures of the tensile fracture surfaces: a alloy 1 ; $\mathbf{b}$ alloy 5

increase the sizes of $\gamma^{\prime \prime}$ and $\gamma^{\prime}$ phases (Fig. 12) and strengthen the matrix surrounding Laves phase and MC carbide (state III in Fig. 5). Therefore, it is more difficult for cracks to propagate toward the matrix surrounding Laves phase and MC carbide. As a result, cracks tend to form and propagate along the interfaces of matrix and particles (Laves and MC) or into the phases (Laves and $\mathrm{MC}$ ) in the alloys with $\mathrm{P}$ addition at the beginning of fracture (Fig. 9b-d). The small holes on the fracture surfaces of alloys with $\mathrm{P}$ addition (Fig. 8b-d) are formed by pulling out Laves phases and MC carbides during fracture. To further verify the above discussion, longitudinal microstructures near the tensile fracture surfaces were further observed (Fig. 13). The cracks propagate toward the matrix surrounding the Laves phases and $\delta$ phases in alloy 1 , and the shadow dimples are formed on the fracture surface (Fig. 13a). However, the cracks propagate along the Laves/matrix interface or into the Laves phases in alloy 5. The holes on the fracture surface of the alloys with $P$ addition are formed by pulling out Laves phases or falling of broken Laves phases (Fig. 13b), which strongly proves the above discussion about the fracture behaviors.

The $\delta$ phases on the grain boundaries can prevent cracks from propagation along the grain boundary [29-31]. With increasing content of $\mathrm{P}$, the precipitations of $\delta$ phases on the grain boundaries are prevented. Lack of the grainboundary phases makes cracks easy to propagate along the grain boundaries. As a result, intergranular cracks are observed on the fracture surfaces of the alloys 3 and 5 (Figs. 7, 8). Moreover, the previous studies demonstrated that small amount of $\mathrm{P}$ was beneficial to the grain-boundary cohesion, while too much $\mathrm{P}$ atoms segregated at the grain boundaries could make the grain boundaries brittle [32-34]. So the intergranular fracture region is observed on the fracture surface of alloy 5 due to the high P content at the grain boundary (Fig. 8d).
The discussion above indicates that the $\delta$ phases on the grain boundaries are beneficial to tensile plasticity, and the needle-like $\delta$ phases in the interdendritic regions are harmful. There are many needle-like $\delta$ phases in the interdendritic regions of alloy 1 , so the reduction of area is small. With increasing content of $\mathrm{P}$, the needle-like $\delta$ phases in the interdendritic regions are inhibited (Fig. 3), which increases the reduction of area (Fig. 6). However, increasing the $\mathrm{P}$ content continuously, although the needlelike $\delta$ phases almost disappear in the interdendritic regions, intergranular cracks occur easily (Fig. 7), and the residual primary Laves phases (brittle phase) in interdendritic regions are much more (Fig. 3), so the reduction of area is decreased (Fig. 6). The good thing is that the reduction of area of alloy 5 is not lower than that of alloy 1 . Unlike the reduction of area, the elongation is the same when the $\mathrm{P}$ content (wt\%) is lower than 0.022 (Fig. 6). The elongation mainly happens in the early stage of the tensile deformation, when the stress reaches a critical level, plastic deformation will occur at the weakest part of the test sample and the necking happens. All additional deformations mainly concentrate in this necking region, and then, cracks generate and propagate quickly [35]. Although the needle-like $\delta$ phases in the interdendritic regions facilitate the generation and propagation of the cracks and significantly affect the reduction of area, its effect on elongation is less obvious. The previous study revealed that the volume fraction of $\delta$ phase in the matrix did not significantly affect the elongation of IN718 alloy [31], which totally consists with the results in this paper.

\section{Conclusions}

It is generally deemed that phosphorus tends to be segregated at the grain boundaries, so its effect on $\gamma^{\prime \prime}$ and $\gamma^{\prime}$ phases in grain interior and tensile strength can be ignored 
in IN718 alloy. However, different results are revealed as follows:

1. $\mathrm{P}$ can accelerate the precipitations of $\gamma^{\prime \prime}$ and $\gamma^{\prime}$ phases during air cooling in IN718C alloy and strengthen the matrix markedly, and the amounts of $\gamma^{\prime \prime}$ and $\gamma^{\prime}$ phases increase with increasing $\mathrm{P}$ content. $\mathrm{P}$ can also increase the sizes of $\gamma^{\prime \prime}$ and $\gamma^{\prime}$ phases after double aging and improve the micro-hardness and tensile strength, but the sizes of the two phases and the tensile strength increase first and then stay invariable with increasing $P$ content. It indicates that $\mathrm{P}$ atom can be dissolved in the grain interior of IN718C alloy to a relatively high degree at high temperature, and its effect on the grain interior is remarkable.

2. The effects of $\mathbf{P}$ on both grain interior and grain boundary are significant in IN718C alloy. The precipitation of $\delta$ phases both in grain interior and on grain boundary is inhibited markedly by $\mathrm{P}$, and the inhibitory effect of $\mathrm{P}$ on $\delta$ phases is enhanced with increasing content of $\mathrm{P}$. Controlling the $\delta$ phases in a moderate $\mathrm{P}$ content can get the optimal tensile plasticity of IN718C alloy.

3. The synthetical effects of $\mathrm{P}$ on $\gamma^{\prime \prime}, \gamma^{\prime}$ and $\delta$ phases in matrix can change the crack propagation path from the matrix around the particles (Laves phases and MC carbides) to the interfaces of the matrix and the particles (Laves phases and MC carbides) at the beginning of tensile fracture.

Acknowledgements This research is supported by the National Key Research and Development program of China (Nos. 2017YFB0701803 and 2016YFB0701403) and State Key Laboratory of Nickel and Cobalt Resources Comprehensive Utilization.

\section{References}

[1] R. Holt, W. Wallace, R. Holt, W. Wallace, Int. Met. Rev. 21, 1 (1976)

[2] S.H. Song, Y. Zhao, Y. Cui, J. Sun, H. Si, J.Q. Li, Mater. Lett. 182, 328 (2016)

[3] W.R. Sun, S.R. Guo, D.Z. Lu, Z.Q. Hu, Metall. Mater. Trans. A 28, 649 (1997)

[4] S. Guan, C. Cui, Y. Yuan, Y. Gu, Mater. Sci. Eng. A 662, 275 (2016)

[5] W. Cao, R. Kennedy, Superalloys 1996, 589 (1996)

[6] S. Zhang, Dissertation, University of Chinese Academy of Sciences, 2015

[7] W.R. Sun, S.R. Guo, B.Y. Tong, D.Z. Lu, Y. Xu, X.N. Meng, N. Li, Z.Q. Hu, J. Mater. Sci. Technol. 19, 289 (2003)
[8] Z. Zhai, H. Abe, Y. Miyahara, Y. Watanabe, Corros. Sci. 92, 32 (2015)

[9] M.V. Sorokin, Z.V. Lavrukhina, A.N. Khodan, D.A. Maltsev, B.S. Bokstein, A.O. Rodin, A.I. Ryazanov, B.A. Gurovich, Mater. Lett. 158, 151 (2015)

[10] X.B. Liu, J.X. Dong, B. Tang, X.H. Hu, X.S. Xie, Mater. Sci. Eng. A 270, 190 (1999)

[11] M. Wang, J. Du, Q. Deng, Z. Tian, J. Zhu, Mater. Sci. Eng. A 626, 382 (2015)

[12] W.R. Sun, S.R. Guo, J. Lee, N. Park, Y. Yoo, S. Choe, Z. Hu, Mater. Sci. Eng. A 247, 173 (1998)

[13] J.A. Horton, C.G. Mckamey, M.K. Miller, W.D. Cao, R.L. Kennedy, Superalloys 718, 625, 706 and various derivatives. In: E.A. Loria (eds) Proceedings of the Sixth International Symposium on Superalloys 718, 625, 706 and Derivatives Sponsored by the Structural Materials Division (SMD) of TM. The Minerals, Metals and Materials Society, Warrendale (1997)

[14] L. Zheng, T. Xu, Q. Deng, J. Dong, Mater. Lett. 62, 54 (2008)

[15] Z. Jie, J. Zhang, T. Huang, L. Liu, H. Fu, J. Alloys Compd. 706, 76 (2017)

[16] Z.J. Miao, A.D. Shan, Y.B. Wu, J. Lu, Y. Hu, J.L. Liu, H.W. Song, Trans. Nonferrous Metal. Soc. 22, 318 (2012)

[17] Z.J. Miao, A.D. Shan, J. Lu, H.W. Song, Mater. Sci. Technol. 28, 334 (2012)

[18] S. Zhang, X. Xin, W.R. Sun, X.F. Sun, L.X. Yu, Y.C. Zhang, Z.Q. Hu, Trans. Nonferrous Metal. Soc. 25, 2939 (2015)

[19] J.T. Guo, L.Z. Zhou, Superalloys 781, 451 (1996)

[20] E. Hondros, M. Seah, Int. Met. Rev. 22, 262 (1977)

[21] D.H. Ping, Y.F. Gu, C.Y. Cui, H. Harada, Mater. Sci. Eng. A 456, 99 (2007)

[22] W.R. Sun, S.R. Guo, Z.Q. Hu, Acta. Metall. Sin. (Engl. Lett.) 9 , 443 (1996)

[23] W.S. Xu, X.P. Yang, W.Z. Zhang, Acta. Metall. Sin. (Engl. Lett.) 31, 1 (2018)

[24] M. Fisk, J. Ion, L.E. Lindgren, Comput. Mater. Sci. 82, 531 (2014)

[25] Y. Ji, Y. Lou, M. Qu, J.D. Rowatt, F. Zhang, T.W. Simpson, L.Q. Chen, Metall. Mater. Trans. A 47, 3235 (2016)

[26] M. Sundararaman, P. Mukhopadhyay, S. Banerjee, Metall. Mater. Trans. A 23, 2015 (1992)

[27] A. Devaux, L. Nazé, R. Molins, A. Pineau, A. Organista, J. Guédou, J. Uginet, P. Héritier, Mater. Sci. Eng. A 486, 117 (2008)

[28] Z.J. Miao, A.D. Shan, J. Lu, H.W. Song, Mater. Sci. Technol. 27, 1551 (2011)

[29] J. An, L. Wang, Y. Liu, W. Cai, X. Song, Mater. Sci. Eng. A 684, 312 (2017)

[30] R.G. Carlson, J.F. Radavich, Superalloys, 79 (1989)

[31] M. Anderson, A.L. Thielin, F. Bridier, P. Bocher, J. Savoie, Mater. Sci. Eng. A 679, 48 (2017)

[32] W. Liu, C. Ren, H. Han, J. Tan, Y. Zou, X. Zhou, P. Huai, H. Xu, J. Appl. Phys. 115, 43 (2014)

[33] M.R. Chellali, L. Zheng, R. Schlesiger, B. Bakhti, A. Hamou, J. Janovec, G. Schmitz, Acta Mater. 103, 754 (2016)

[34] K. Wang, C. Yang, H. Si, Mater. Sci. Eng. A 587, 228 (2013)

[35] R.W. Hertzberg, Deformation and Fracture Mechanics of Engineering Materials, 4th edn. (Wiley, Heidelberg, 1996), pp. $19-20$ 